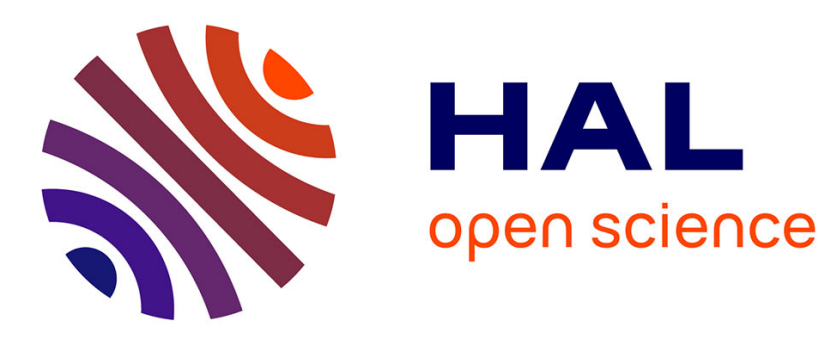

\title{
Organic photodiode for detection of herbicides in water using microalgal photosynthesis
}

\author{
Vincent Ventalon, Fadhila Sekli-Belaidi, R. Izquierdo, P. Juneau, Aliki \\ Tsopela, Jérôme Launay, Véronique Bardinal, Pierre Temple-Boyer, Ludovic \\ Salvagnac, Isabelle Séguy, et al.
}

\section{To cite this version:}

Vincent Ventalon, Fadhila Sekli-Belaidi, R. Izquierdo, P. Juneau, Aliki Tsopela, et al.. Organic photodiode for detection of herbicides in water using microalgal photosynthesis . IEEE-NMDC 2016 , Oct 2016, toulouse, France. hal-01394634

\section{HAL Id: hal-01394634 \\ https://hal.laas.fr/hal-01394634}

Submitted on 9 Nov 2016

HAL is a multi-disciplinary open access archive for the deposit and dissemination of scientific research documents, whether they are published or not. The documents may come from teaching and research institutions in France or abroad, or from public or private research centers.
L'archive ouverte pluridisciplinaire HAL, est destinée au dépôt et à la diffusion de documents scientifiques de niveau recherche, publiés ou non, émanant des établissements d'enseignement et de recherche français ou étrangers, des laboratoires publics ou privés. 


\title{
Organic photodiode for detection of herbicides in water using microalgal photosynthesis
}

\author{
V. Ventalon, F. Sekli, R. Izquierdo, P. Juneau, A. Tsopela, J. Launay, V. Bardinal, P. Temple-Boyer, \\ L. Salvagnac, I. Séguy, E. Bedel-Pereira
}

\begin{abstract}
The growing interest for monitoring the quality of water has triggered the need of fast, portable and cheap detection systems. To answer this problematic, we developed a lab on a chip for herbicide detection based on micro algal photosynthesis. A blue organic light-emitting diode is used as the excitation source while the resulting algae luminescence is monitored using an organic photodiode (OPD). During the OPD optimization process, a correlation between fullerene acceptor concentration and dark current was supposed. Using a blend of DTS(PTTh2) $2:$ PC $_{60} B M$ without interfacial layers result in dark current lower than $10^{-6} \mathrm{~mA} / \mathrm{cm} 2$ at $-2 \mathrm{~V}$ and $\mathrm{EQE}$ higher than $50 \%$ in the region of interest.
\end{abstract}

\section{INTRODUCTION}

Herbicides easily penetrate the soil, degrade slowly and accumulate in the environment particularly in river and groundwater [1]. Their detection and quantification are done in laboratory, using gas and liquid spectroscopy for product separation and mass spectroscopy is mostly used for quantification and identification of products. These techniques are very sensitive, selective and robust [2]. However, these protocols are costly in term of money and time. For a better monitoring of water quality, there is a need of rapid and low-cost on-site analysis systems.

Biosensors are analytical tools that used a biological element to interact with the analyte and a transducer to measure biological changes. By their nature, herbicides have a high impact on microorganism like algae making them ideal bioreceptors. Both luminescence and $\mathrm{O}_{2}$ production are affected through photosynthesis perturbation [3]. Fast herbicides impact permits measurements to be done within a few minutes with great sensitivity and low limit of detection [4-5].

The lab on chip developed presents a microfluidic channel to inject mixture of the sample solution and algae Chlamydomonas reinhardtii in the analysis chamber. An organic light-emitting diode (OLED) and an organic photodiode (OPD) are disposed on each side of the fluidic chamber as excitation and detection systems respectively (Fig. 1). In accordance with algae absorbance (Fig. 2), a blue OLED (400 - $550 \mathrm{~nm}$ emission range) is used to stimulate algae photosynthesis process without interfering with algae luminescence signal. A $550 \mathrm{~nm}$ long pass excitation filter (Fig. 1) is associated to the optical detection in order to prevent excitation light to reach the OPD.

V. Ventalon (corresponding author, phone: +33 6420631 05; e-mail: vventalo@laas.fr), F. Sekli, V. Bardinal, R. Izquierdo, P. Juneau, J. Launay, P. Temple-Boyer, L. Salvagnac, I. Séguy, A. Tsopela and E. Bedel-Pereira are with CNRS, LAAS, 7 avenue du colonel Roche, F-31400 Toulouse, France and Université de Toulouse, UPS, LAAS, F-31400 Toulouse, France. R. Izquierdo and P. Juneau are with Université du Québec à Montréal ; 201 Président Kennedy ; Montréal, Canada.

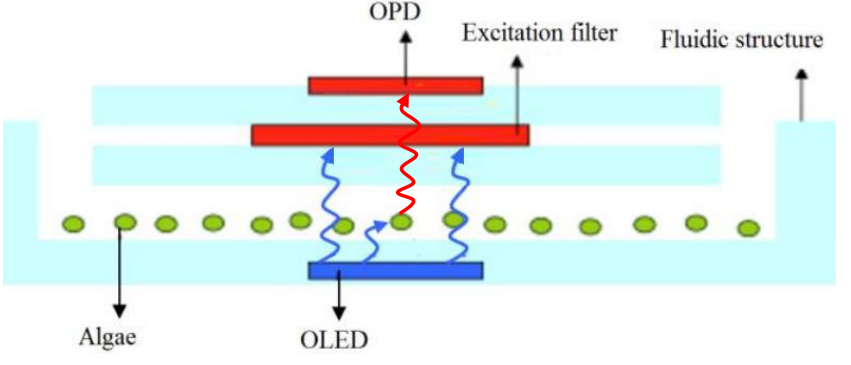

Figure 1: Schematic overview of the lab on chip.

\section{ORGANIC PHOTODIODE}

The prerequisite for photodiode integration in optical sensor systems is: (i) high external quantum efficiency (EQE) matching with biosensor emission spectra, and (ii) low dark current i.e. high "on/off" ratio in order to detect small luminescence intensities. OPD are a promising alternative to silicon-based photodetectors. They present high sensitivity in visible wavelength range, low dark current and are cheap to manufacture [6]. The basic structure of an OPD is an organic heterojunction constituted of an electron donor (D) and an electron acceptor (A) sandwiched between metallic and transparent electrodes.

In our system, the choice of D and A OPD materials is fixed by Chlamydomonas reinhardtii maximum luminescence emission at $700 \mathrm{~nm}$ (Fig.2). Hence, new low band gap donor molecules or polymers associated with fullerene derivatives are promising for our application [7]. They show power conversion efficiency (PCE) above 9\% highly due to strong light harvesting and electronic conversion between $500 \mathrm{~nm}$ and $750 \mathrm{~nm}$. In this work, small molecules are preferred because it means more batch-to-batch reproducibility, which is required to develop stable monitoring systems.

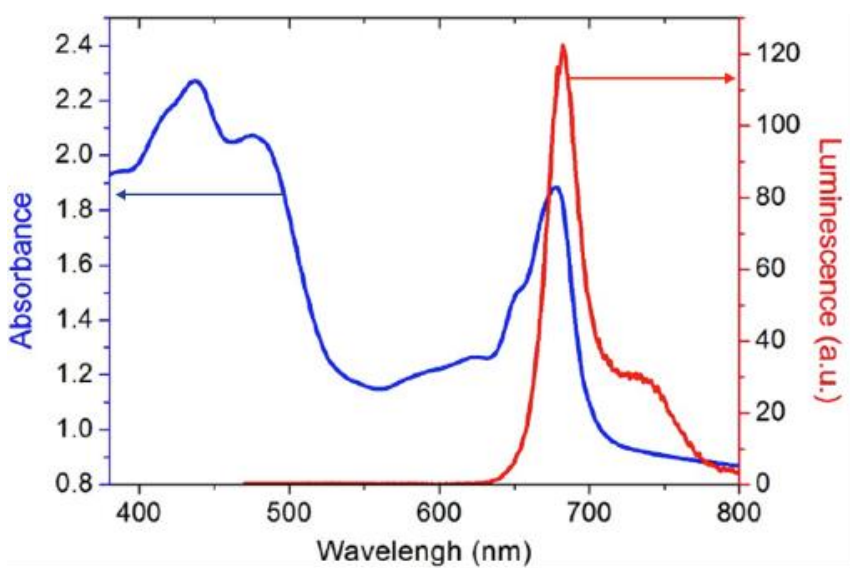

Figure 2: Absorbance (blue line) and luminescence (red line) of $6 \times 10^{6}$ cells of Chlamydomonas reinhardtii per milliliter of water. 
Thus, we choose to study OPD based on 5,5'-bis\{(4-(7hexylthiophen-2-yl)thiophen-2-yl)- $\quad[1,2,5]$ thiadiazolo[3,4c]pyridine \}-3,3'-di-2-ethylhexylsilylene- 2,2'-bithiophene $\mathrm{DTS}\left(\mathrm{PTTh}_{2}\right)_{2}$ as electron donor (D) associated with $[6,6]-$ phenyl-fulleren (C60 or C70)-butanoate methyl (PCBM) which seems to fit with the LoC system [8].

\section{Photodiode OptimizATION}

The studied OPD structure is ITO/ DTS(PTTh $)_{2}$ :A (100 nm) /Al with $\mathrm{PC}_{60} \mathrm{BM}$ or $\mathrm{PC}_{70} \mathrm{BM}$ as $\mathrm{A}$ materials. DTS $\left(\mathrm{PTTh}_{2}\right)_{2}$ and fullerene derivatives are dissolved in warm chlorobenzene to obtain $40 \mathrm{mg} \cdot \mathrm{ml}^{-1}$ concentration solutions with D:A mass ratio of 70:30. Films are spin-casted at 1600 rpm for $60 \mathrm{~s}$ and annealed $10 \mathrm{~min}$ at $70{ }^{\circ} \mathrm{C}$ to remove residual solvent. Finally, $150 \mathrm{~nm}$ aluminum electrodes are evaporated on top of the bulk heterojunction (BHJ).

First tests performed with these two structures without any device optimization have shown encouragingly low dark current and reproducibility. Indeed, many ways are used to improve OPD performances like adding interfacial layers between electrodes and organic semiconductors to significantly reduce dark current. These layers act as blocking pathways for unwanted charges injection under reverse bias [9]. Active layer morphology can also have a significant impact on charges separation and leakage current [10].

$\mathrm{PC}_{60} \mathrm{BM}$ and $\mathrm{PC}_{70} \mathrm{BM}$ seem similar but generate very different $\mathrm{BHJ}$ thin films morphologies. Current-voltage characteristics performed in dark and under $680 \mathrm{~nm}$ illumination evidence that both of them provide similar charge photo-conversion in the desired wavelength area. However, $\mathrm{PC}_{70} \mathrm{BM}$ displays slightly higher dark current (see bottom curve Fig. 3).

The speed of spin coating is also investigated for 1000 , 1600 and $2000 \mathrm{rpm}$ for $\mathrm{PC}_{60} \mathrm{BM}$ to follow changes on film thickness or $\mathrm{PC}_{60} \mathrm{BM}$ aggregation. Films spin coated at 1000 rpm were not uniform in contrast with films spin coated at 1600 and $2000 \mathrm{rpm}$ that lead to similar device behavior.

Finally, the impact of D:A weight ratio on charges separation and dark current is studied for 60:40 to 80:20 BHJs. The dark current significantly decreases with smaller amount of $\mathrm{PC}_{60} \mathrm{BM}$. Many changes in $\mathrm{EQE}$ are also observed and will be discussed.

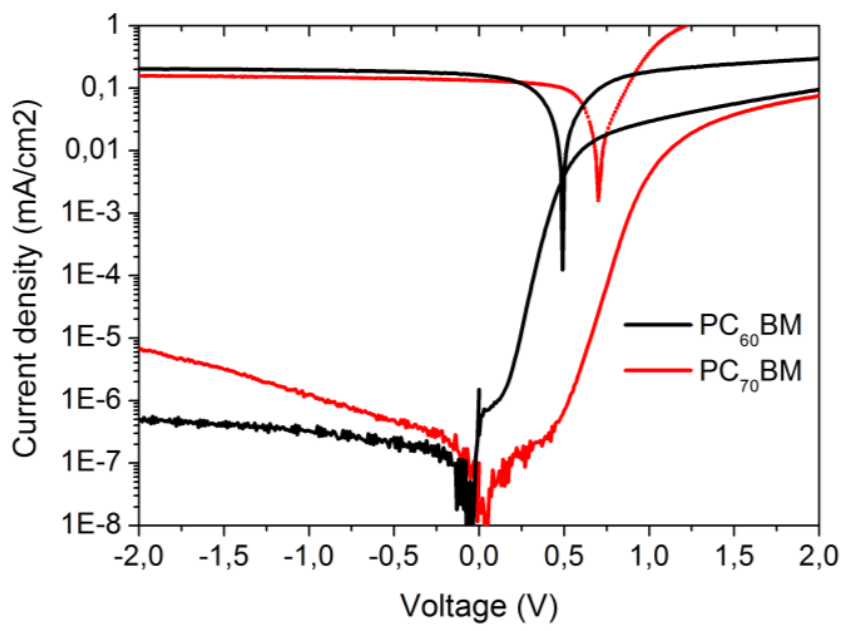

Figure 3: Dark current (bottom lines) and photogenerated current (upper lines) for $680 \mathrm{~nm}$ wavelength for $\mathrm{PC}_{60} \mathrm{BM}$ (dark line) and $P C_{70} \mathrm{BM}$ (red line).

\section{ACKNOWLEDGMENT}

The authors would like to thank the French "Agence nationale de la Recherche" (ANR, project DOLFIN, no. ANR-13-JS03-0005-01) and the Fonds France-Canada pour la Recherche (FFCR) for financing the project. Furthermore, microfabrication procedure was partly supported by the French RENATECH network. The authors thank also Bernard Franck for his help in the design of OPD and OLED characterization benches.

\section{REFERENCES}

[1] H. J. Stan, Analysis of Pesticides in Ground and Surface Water, Vol. 1, Springer-Verlag Berlin Heidelberg, 1995.

[2] World Health Organization "Guidelines for Drinking-water Quality: Recommendations" Vol. 1, $3^{\text {rd }}$ ed. 2004.

[3] R. Brayner, "Micro-algal biosensors", Anal. Bioanal. Chem., 401, pp. 581-597, 2011.

[4] A.Tsopela, "Development of a lab-on-chip electrochemical biosensor for water quality analysis based on microalgal photosynthesis", Biosensors and Bioelectronics, Vol. 79, pp. 568-573, 2016.

[5] F. Lefèvre, "Algal fluorescence sensor integrated into a microfluidic chip for water pollutant detection." Lab on a Chip, Vol.12, pp 787793, 2012.

[6] B. Bouthinon "Impact des états de gap sur les performances des photodiodes organiques" Ph.D dissertation, University of Grenoble, 2014.

[7] Tao Xu, "How to design low bandgap polymers for highly efficient organic solar cells", Materialstoday, Vol. 17, pp 11-15.

[8] Alan J. Heeger, "Solution-processed small-molecule solar cells with 6.7\% efficiency”, Nature Materials, Vol. 11, pp 44-48, 2012.

[9] F. Arca, "Organic photodiodes for industrial sensing and medical imaging" Ph.D dissertation, University of Munich, 2013.

[10] E. Keivanidis, "The dependence of device dark current on the activelayer morphology of solution processed organic photodetectors", Advanced functional materials, Vol. 20 pp 3895-3903, 2010. 